\title{
In-School Adolescents' Attention to Communication Interventions on Open Defecation
}

\author{
Allen Nnanwuba Adum \\ Department of Mass Communication, Nnamdi Azikiwe University, Awka, \\ Anambra State, Nigeria \\ Ogochukwu Ekwenchi \\ Department of Mass Communication, Nnamdi Azikiwe University, Awka, \\ Anambra State, Nigeria \\ Chioma Agbasimelo \\ Department of Mass Communication, Tansian University, Umunya, \\ Anambra State, Nigeria \\ Ekene Godfrey Okafor \\ Department of Mass Communication, Nnamdi Azikiwe University, Awka, \\ Anambra State, Nigeria
}

\begin{abstract}
The practice of open defecation has been recognized as one of the leading threats to human health and one of the world's leading causes of diseases such as acute diarrhea, cholera, dysentery, hepatitis, typhoid, intestinal worms etc. This study examined whether in-school students in Anambra State, Nigeria, engage in the practice and how they internalize the communication interventions targeted at getting rid of the practice among them. This is in view of the PEWASH Program (Partnership for Expanded Water Supply, Sanitation \& Hygiene, 2015), and the National road map of "Making Nigeria Open Defecation Free by 2025 " developed by the Federal Ministry of Water Resources with support from UNICEF and other key players across Nigeria. The design for this study was survey. The study population comprised 129,289 In-school adolescents in Anambra State, covering only public Schools under the Anambra State Post Primary Schools Service Commission (PPSSC). A sample size of 402 was drawn based on Yamane and Meyer's suggestions. The study found that the students were entirely aware of the interventions but only 5\% of them were aware of the Federal government PEWASH campaign. While 57\% of them received the interventions via word of mouth, others did so through Television (9\%); radio (18\%); posters $(1 \%)$ and then writings on some walls $(14 \%)$. This study also revealed that the interventions they were mostly exposed to were the warnings by the school management that they should not defecate in the open or litter the school premises. We strongly recommended sensitization campaigns on the issue of open defecation as one way of checking the practice; especially among In-school adolescents.
\end{abstract}

Keywords: In-school adolescents, Interventions, Attention, Responses, open defecation

DOI: $10.7176 / \mathrm{JCSD} / 49-07$

Publication date:June $30^{\text {th }} 2019$

\section{Background of the Study}

Nigeria is reportedly among the nations in the world with the highest number of people practicing open defecation. Empirical evidence shows that open defecation could lead to infant deaths; pollution of ground waters, contamination of agricultural produce, and spread of diseases such as diarrhea, cholera and bilharza (Boisson, Sosai, Ray, Routray, Torondel, Schmidt, Bhanja, and Clasen, 2014). These had ignited the initiative tagged "Making Nigeria Open Defecation Free by 2025: A National Roadmap", developed by the Federal Ministry of Water Resources with support from UNICEF and other key sector players across Nigeria (Adamu, 
2017, p. 1). This roadmap was endorsed by the National Council on Water Resources in 2016 as a means to eliminate open defecation in Nigeria and provides a guide towards achieving an open defecation free country using different approaches such as capacity development; promotion of improved technology options through sanitation marketing; provision of sanitation facilities in public places; Community-Led Total Sanitation; promotional and media campaigns; creating enabling environment and coordination mechanism (Adamu, 2017, p. 2).

The Roadmap also provides a basis for the development of the Partnership for Expanded Water Supply and Sanitation (PEWASH) programme which aims to establish a multi-sectoral partnership between government, development partners and the private sector to support the empowerment of rural dwellers in Nigeria through the provision of adequate water supply and sanitation services (Awe \& Nadar, 2016, p. 2).

The (PEWASH) is a National collaboration for the improvement of access to water supply and sanitation in Nigeria, through a structured multi-sector partnership designed to build on previous efforts and complement existing water supply and sanitation strategies by instituting a coordination and prioritization framework for project delivery. It also provides an opportunity for the water and sanitation sector to leverage the plentitude of expertise, technology and financial resources from the government (Federal, State, and Local), development partners, the private sector, civil society and community (Adamu, 2017) also broken down into three phases, with phase-I (2016-2018) being the Preparatory phase; phase-II (2019-2025) being the expansion phase and finally phase-III (2026-2030) is the acceleration phase.

One of the primary objectives of the PEWASH programme is to prioritize the achievement of $100 \%$ access to water supply and improved sanitation in rural areas by the year 2030, and eliminate open defecation by 2025 . The National Task Group on Sanitation (NTGS) coordinates sanitation and hygiene campaign in Nigeria through engagement in advocacy, sensitization and promotion of sanitation programmes. PEWASH is to strengthen the capacity of the NTGS to scale up their interventions towards eliminating open defecation in the country in-line with the National Road Map on elimination of Open Defecation. PEWASH is to enhance execution of activities aimed at ensuring an environment free of water borne diseases through behavioural change. Some of the activities to be carried out, according to the PEWASH campaign include;

- Approval of the National ODF (Open Defecation Free) Road Map for Nigeria

- Strengthening of the NTGS (National Task Group on Sanitation) through capacity development

- High level advocacy to Governors, Ministers, Parliamentarians and Commissioners including engagement of wives of Governors as Champions/Advocates to support commitment to CLTS (Community led total sanitation) implementation.

- National launch to end open defecation campaign

- Training and re-training of CLTS implementers in 36 states and FCT.

- Build on ongoing CLTS implementation in all states to incorporate components such as sanitation marketing to increase the effectiveness of the approach and achieve uptake at scale

- Introduce sanitation approaches targeted at Internally Displaced Persons (IDP) in camps

- Hygiene promotion in 36 states and FCT

Although deaths through WASH-related illnesses can be reduced by $5-10 \%$ and up to $20 \%$ through access to good latrines and flush toilets respectively (Jeuland, Fuente, Ozdemir, Allaire, \& Whittington 2013, p. 5), WHO (2008) had disclosed that $55 \%$ of children's death in rural areas could be prevented through WASH interventions, reduction in the practice open defecation. The Federal Ministry of Water Resources is also to provide the enabling environment, leadership and coordination required in achieving this target by working together with communities, civil society, development agencies, private sector and government at sub-national levels (Adamu, 2017, p. 2).

The Roadmap also provides a basis for the development of the Partnership for Expanded Water Supply and Sanitation (PEWASH) programme which aims to establish a multi-sectoral partnership between government, development partners and the private sector to support the empowerment of rural dwellers in Nigeria through the provision of adequate water supply and sanitation services (Awe \& Nadar, 2016, p. 2). The (PEWASH) is also a National collaboration for the improvement of access to water supply and sanitation in Nigeria, through a structured multi-sector partnership designed to build on previous efforts and complement existing water supply and sanitation strategies by instituting a coordination and prioritization framework for project delivery. It will 
also provide an opportunity for the water and sanitation sector to leverage the plentitude of expertise, technology and financial resources from the government (Federal, State, and Local), development partners, the private sector, civil society and community (Adamu, 2017) also broken down into three phases, with phase-I (2016-2018) being the Preparatory phase; phase-II (2019-2025) being the expansion phase and finally phase-III (2026-2030) is the acceleration phase.

One of the primary objectives of the PEWASH programme is to prioritize the achievement of $100 \%$ access to water supply and improved sanitation in rural areas by the year 2030, and eliminate open defecation by 2025 . The National Task Group on Sanitation (NTGS) coordinates sanitation and hygiene campaign in Nigeria through engagement in advocacy, sensitization and promotion of sanitation programmes. PEWASH is to strengthen the capacity of the NTGS to scale up their interventions towards eliminating open defecation in the country in-line with the National Road Map on elimination of Open Defecation. PEWASH is to enhance execution of activities aimed at ensuring an environment free of water borne diseases through behavioural change. Some of the activities to be carried out, according to the PEWASH campaign include;

- Approval of the National ODF (Open Defecation Free) Road Map for Nigeria

- Strengthening of the NTGS (National Task Group on Sanitation) through capacity development

- High level advocacy to Governors, Ministers, Parliamentarians and Commissioners including engagement of wives of Governors as Champions/Advocates to support commitment to CLTS (Community led total sanitation) implementation.

- National launch to end open defecation campaign

- Training and re-training of CLTS implementers in 36 states and FCT.

- Build on ongoing CLTS implementation in all states to incorporate components such as sanitation marketing to increase the effectiveness of the approach and achieve uptake at scale

- Introduce sanitation approaches targeted at Internally Displaced Persons (IDP) in camps

- Hygiene promotion in 36 states and FCT

Although deaths through WASH-related illnesses can be reduced by 5-10\% and up to $20 \%$ through access to good latrines and flush toilets respectively (Jeuland, Fuente, Ozdemir, Allaire, \& Whittington 2013, p. 5), WHO (2008) had disclosed that $55 \%$ of children's death in rural areas could be prevented through WASH interventions, reduction in the practice open defecation. The Federal Ministry of Water Resources is also to provide the enabling environment, leadership and coordination required in achieving this target by working together with communities, civil society, development agencies, private sector and government at sub-national levels (Adamu, 2017, p. 2).

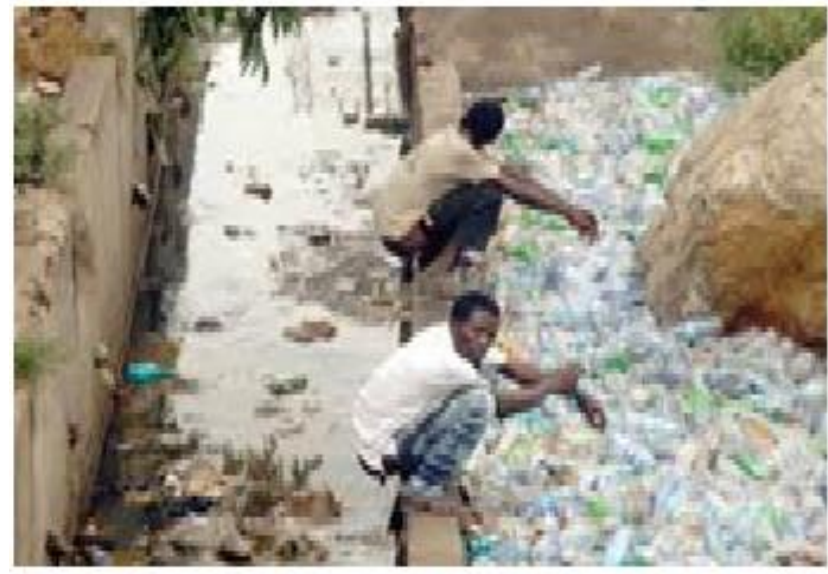

Figure 1: People practicing open defecation

and polluting underground waters

The poor sanitation situation in Nigeria had prompted the National Council on Water Resources in 2014 to prioritize the development of a roadmap towards eliminating open defecation in the country, in line with the 
United Nations global campaign for ending open defecation (Adamu, 2017, 3). It is within this context that this work examines whether the in-school students' in Anambra State are aware of these interventions; whether they pay attention to them; and, possibly adhere to the messages such that a behaviour change can occur.

\section{THE PROBLEM}

It is becoming increasingly difficult to ignore the serious consequences that open defecation has for school-aged children, such as high risk of hygiene-related morbidity and mortality (UNICEF \& IRC 1998; WHO 2009; Lorna, Kaufmann, David, Wayne, Laurence \& Colford 2005). This is because improved sanitation and hygiene practices is fundamental to child survival, socio-economic development and the well being of the society at large. Eliminating open defecation has benefits from the health, nutrition, learning, social and economic perspective; it safeguards girls/women's dignity and protects them against sexual harassment etc (Awe \& Nadar, 2016 p. 1). It remains important not only for improved public health but also for economic and social development of the Nigerian society. It is rather repugnant that eighty eight percent $(88 \%)$ of the world diarrhea cases are attributable to unsafe water, inadequate sanitation or insufficient hygiene (Bill and Melinda Gates Foundation, 2011; WHO \& UNICEF, 2004). While food and water tainted with fecal matter cause up to 2.5 billion cases of acute diarrhea among children, resulting in 1.5 million deaths (Bill and Melinda Gates Foundation, 2011; WHO \& UNICEF, 2004; UNICEF/WHO 2008), Nigeria seems to be off track with regard to the SDG-6 target on water and sanitation.

Besides, Factors such as poor maintenance, smelly and dirty latrines could be seen to be hindering latrine use by school children and in the process lure them to indulge in the practice of open defecation (Vernon, Lundblad \& Hellstrom 2003; Lundblad 2005). Some other factors may include: lack of sanitation facilities (Ebong 1994), and overcrowding (Croghan, 2002). These could arguably play a role on whether children will use the latrines in schools. These premises suggest that when teachers hardly teach children basic hygiene, and when there are insufficient toilet facilities or latrines that are untidy, younger children may likely feel uncomfortable using latrines in such conditions (Nuzhat \& Mohammad 2006). Even at that, there still remains the need to investigate whether these reasons are still obtainable, using the secondary schools in Anambra State Nigeria as the primary focus. Although the aforementioned factors could attribute to rise in the practice of open defecation, severe health hazards remains inevitable when the public, especially students perceive the practice as a norm. It is in recognition of these that this study interrogates the in-school students' attention and adherence to these interventions as well as factors that may inhibit their responses to same.

\section{AIM AND SPECIFIC OBJECTIVES}

This work interrogated the exposure, and adherence of in-school students to communication interventions on open defecation as well as their reasons for possible practice of same. It addressed these research questions:

1. How exposed are in-school adolescents to communication interventions on open defecation?

2. What are the medium of their potential exposure to these Interventions?

3. What is their level of practice of open defecation?

4. What are the reasons behind their possible practice of open defecation?

5. How do they adhere to the interventions?

6. How do the interventions influence change in their behavior?

\section{CONCEPTUALIZING OPEN DEFECATION}

Open defecation is the practice of people defecating outside or in the open and not into a designated toilet. The term is widely used in literature about water, sanitation, and hygiene (WASH) issues in developing countries. Open defecation causes public health problems in areas where people defecate in fields, urban parks, rivers, and open trenches in close proximity to the living space of others (Clasen, Boisson, Routray, Torondel, 2014). 


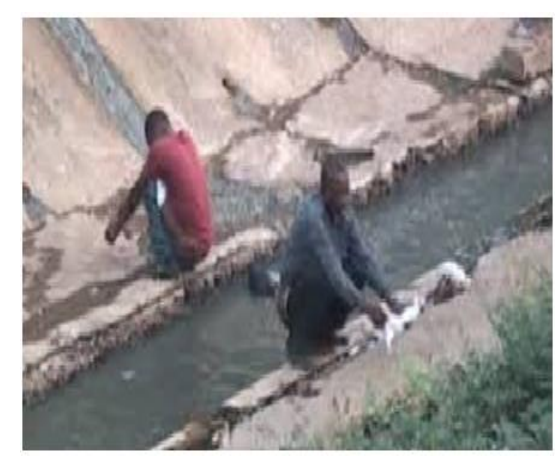

Figure 2: people defecating inside waters

Eliminating this ugly practice should be a proposed indicator for sustainable development and seen as an important part of development efforts (Ahmed, 2014), because high levels of open defecation in a country are usually correlated with high child mortality, as well as high levels of under nutrition, high levels of poverty, and large disparities between rich and poor (WHO, UNICEF, 2014, p 11). Even if toilets are available, people still need to be convinced to refrain from open defecation and use toilets (Clasen, Boisson, Routray, Torondel, 2014). Although a preference for open defecation may be due to traditional cultural practices or lack of access to toilets, or both, the need for behavioral change is critical with regards to the practice of open defecation.

\section{OPEN DEFECATION: THE NIGERIAN SITUATION}

The adverse impact of open defecation in Nigeria has been well documented. Studies have also shown that a large part of malnutrition burden in Nigeria owes to the unhygienic environment in which children grow up with the practice of open defecation (Awe \& Nadar, 2016, p. 3). According to a World Bank Report (2012), around 122,000 Nigerians including 87,000 children under 5 die each year from diarrhoea; nearly $90 \%$ is directly attributed to water, sanitation and hygiene. One of the major reasons for Iron Deficiency Anaemia (IDA) among adolescent girls and young mothers in Nigeria appear to be worm infestation, sometimes attributed to open defecation. It is also not surprising that one in every fifthteenth Nigerian children reportedly dies before reaching his/her first birth day and one in every eight does not survive to see his/her fifth birth day (Awe \& Nadar, 2016, p. 2). These deaths arguably have some relationships with disease sometimes attributed to open defecation and poor hygiene practices. In consideration of these, the present Open defecation Free (ODF) Roadmap is an attempt to articulate the strategies, plans and investments needed to eliminate the practice by 2025; and, achieving an ODF environment implies having access to toilets not only in the communities but also within schools, health centres, markets and other public places (Awe \& Nadar, 2016, p. 3). The roadmap is organized along the following sections:

- Current sanitation situation;

- Past efforts and lessons learned in the implementation of sanitation programmes;

- Rationale, suggested strategies and action plan,

- Phasing for implementing the road map,

- Roles and responsibilities of key stakeholders,

- Implementation plan

- The required enabling environment; and,

- Investment needs for eliminating open defecation by 2025(Awe \& Nadar, 2016, p. 2).

Although achieving an ODF in Nigeria may require constructing nearly 20 million household toilets and 43,000 toilets in schools, health centres and public places, the implementation of the roadmap is projected to be in phases - the initial preparatory phase, followed by the consolidation phase and then the final assault phase sequel to the Government of Nigeria seeming commitment to end the practice in the country by 2025 which is in line with the revised global target set by the United Nations (Awe \& Nadar, 2016, p. 3).

In Nigeria, Open defecation arguably constitutes one of the biggest threats to human health and one of the world's biggest cause of infection (UN-Habitat, 2003; Canaday, 2011) especially the waterborne diseases such as acute diarrhea, cholera, dysentery, hepatitis, typhoid, and intestinal worms (Bill and Melinda Gates Foundation, 2011; Conant and Fadem, 2008). These problems had ignited positive reactions by the administration of 
Governor Willie Obiano in Anambra State, Nigeria, whereby potable water and sanitary facilities are made available in some rural communities and schools in the State.

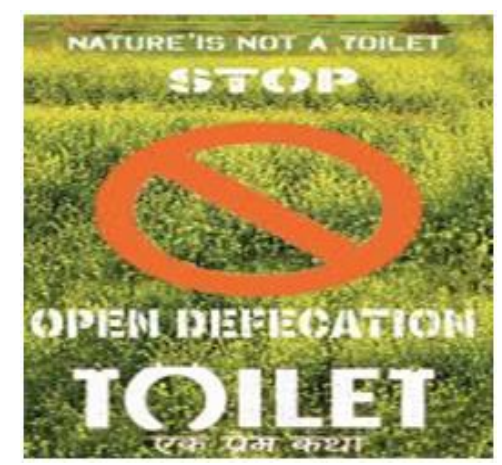

Figure 4: some of the communication

interventions on open defecation by

\section{UNICEF}

Apart from that, Open defecation is not only a social stigma but also a factor contributing to sexual harassment and violence against young girls and young married women. For instance, a study sponsored by Water Aid in selected slums in Lagos found that some women defecating in the open, had either first or second hand experience of harassment, a threat of violence or actual assault (Awe \& Nadar, 2016, p. 2)

Besides, it has also been observed by the PEWASH (Partnership for Expanded Water Supply, Sanitation \& Hygiene, 2015), that countries where open defecation is most widely practiced are the same countries with the highest level of poverty, high number of under-five child deaths, and wealth disparities. The most vulnerable seem to be those people living in large agglomerations under unsanitary conditions in developing countries where waste water goes straight into the environment without treatment, thus the fecal contamination of their environment is even more direct (UN-Habitat, 2003; Canaday 2011). In consideration of these, the World Toilet Organization in 2001 declared November 19 as World Toilet Day to raise global awareness of the struggle 2.6 billion people face every day who have no access to clean sanitation, despite its consequences (Bill and Melinda Gates Foundation, 2011).

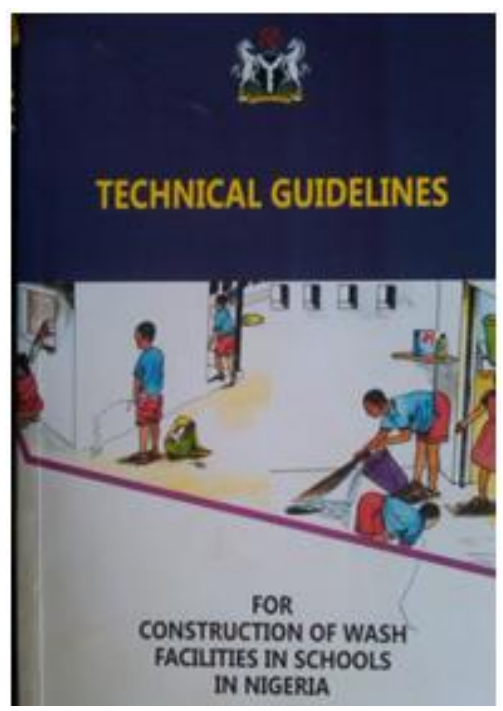

Figure 5: Some of the interventions wash

campaigns in affiliation with to

open defecation 
Thus some people in developing countries still use the on-site systems of faeces disposal such as pit or bucket latrines and in such situations, waste does not decompose fast enough or completely, so the pits or bucket toilets fill up fast, leading to flies, odours, and unpleasant conditions (Arku, Vallarino, Dionisio, Hyunok, Wilson, Hemphill, Agyei-Mensah, Spengler, \& Ezzati 2008). This therefore shows that a relationship exists between the practice of open defecation and scarcity of good toilet facility

Open defecation can thus contribute to Nigeria's failure to meet the SDG target; pose a high risk of hygiene-related morbidity and mortality among school-aged children. (UNICEF, IRC: 1998; World Health Organization, 2009) and perpetuate a vicious cycle of disease and poverty. Perhaps, this formed part of the reasons the National Council on Water Resources in 2014 embarked on the National road map of "Making Nigeria Open Defecation Free by 2025" developed by the Federal Ministry of Water Resources with support from UNICEF and other key sector players across Nigeria.

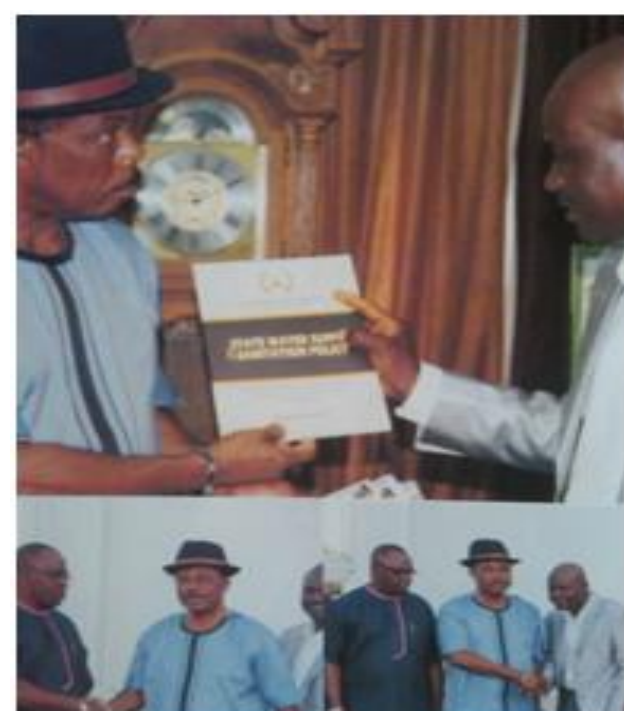

Figure 3: The Anambra State Governor and wife

crusading against the practice of open and

providing water and sanitary

facilities for some rural Communities

The Governor of Anambra State, Nigeria, and his wife, in collaboration with UNICEF and European Union, had also been crusading for and looking at programs that will make the State Communities Open Defecation Free (ODF), which had led Anambra Communities claiming to be open defecation free. In fact, the State had embarked on community and schools development projects of providing potable water and toilet facilities. This study, in line with these developments determined whether and why the in-school students in Anambra State may engage in the practice and how communication interventions against the practice may help reduce this incidence of diseases within the society and also whether the interventions have any behavior change effect on them.

\section{METHODOLOGY}

The design for this study was Survey; with the questionnaire as the research instrument. The theoretical population involves all the in-school students in Anambra State Public Schools under the Post Primary Schools Service Commission (PPSSC) with an estimate of 129,289 students according to the records of the Commission as well as the State Ministry of Education as at the time of the study. But our working population was the total of 3,190 students from six selected secondary schools. A breakdown of this population is shown in Table 1 . 
Table 1: Sample Frame

\begin{tabular}{|c|c|c|c|c|}
\hline PPSSC Zones & Local Government Areas Covered & $\begin{array}{c}\text { Senatorial Zones covered } \\
\text { within the Zones }\end{array}$ & $\begin{array}{l}\text { Number of Schools in the } \\
\text { Zones }\end{array}$ & $\begin{array}{l}\text { population of students } \\
\text { in each zone }\end{array}$ \\
\hline Aguata & $\begin{array}{c}\text { Aguata, Orumba North \& Orumba } \\
\text { South }\end{array}$ & Anambra south & 49 & 22,765 \\
\hline Awka & $\begin{array}{c}\text { Awka South, Awka North, } \\
\text { Dunukofia, Anaocha and Njikoka }\end{array}$ & Anambra central & 60 & 25,319 \\
\hline Nnewi & $\begin{array}{c}\text { Nnewi North, Nnewi South, } \\
\text { Ekwusigo and Ihiala }\end{array}$ & Anambra South & 47 & 22,942 \\
\hline Ogidi & Idemili North, Idemili South, Oyi & $\begin{array}{l}\text { Anambra central central } \\
\text { And Anambra North }\end{array}$ & 40 & 20,828 \\
\hline Onitsha & $\begin{array}{c}\text { Onitsha North, Onitsha South, } \\
\text { Ogbaru }\end{array}$ & Anambra north & 33 & 20,662 \\
\hline Otuocha & $\begin{array}{c}\text { Anambra East, Anambra West, } \\
\text { Anyamelum }\end{array}$ & Anambra north & 28 & 16,773 \\
\hline Total & 21 & & 257 & 129,289 \\
\hline
\end{tabular}

Meanwhile, a sample size of 402 was also drawn, looking at different samples prescribed by Meyer (1973) for population that range from 1000 to infinity at 95\% confidence level and Taro Yamane's formula for determining sample size $\mathrm{n}=\mathrm{N} / 1+\mathrm{N}(\mathrm{e})^{2}$

The sampling technique adopted for sample selection was the multi stage probability sampling technique which involves series of sampling processes at various levels of the population. The post Primary Schools Service Commission has Six (6) Zones, and three (3) zones out of them were represented. The Six (6) zones are: Aguata, Awka, Nnewi, Ogidi, Otuocha and Onitsha, while the three selected one include: Aguata, Awka and Onitsha Zones.

The selection was made, taking cognizance of the three senatorial zones in the State. From each of the three zones, one local government area was also selected from which one (1) town was selected. And then, two secondary schools selected to represent each of them towns. This process is shown in Table 3.

Table 2: Population and Sample of the Schools

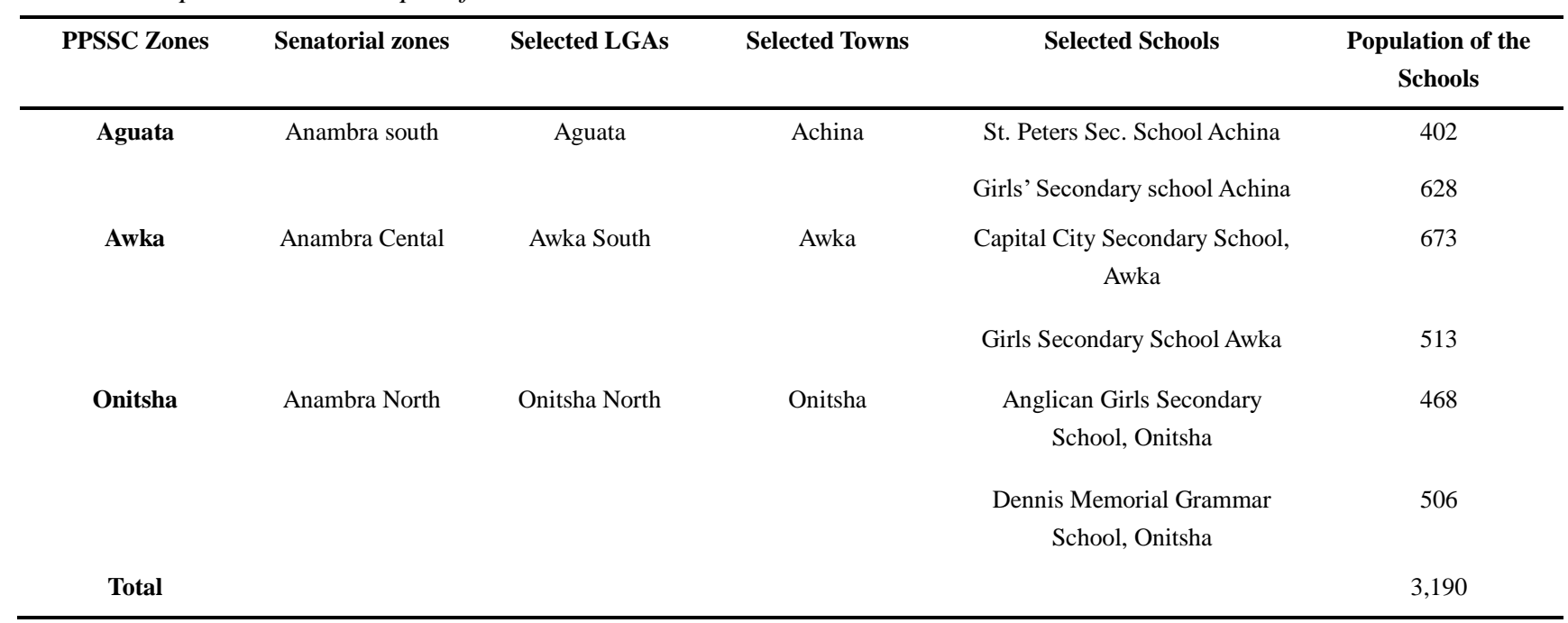

The working population is 3,190 students, distributed among the six selected schools. Each school was allotted 67 students. A purposive decision was made to include only the students in senior classes (SS1-SS3) in the belief that they could be more exposed to the communication interventions on open defecation. This decision is 
illustrated in Table 3.

Table 3: Sample of the Students

\begin{tabular}{|c|c|c|c|}
\hline Selected Schools & Classes & $\begin{array}{l}\text { Number allotted to each } \\
\text { class }\end{array}$ & Total \\
\hline \multirow{3}{*}{$\begin{array}{c}\text { St. Peters Sec. School, } \\
\text { Achina }\end{array}$} & SS1 & 20 students & \multirow{3}{*}{67 students } \\
\hline & SS2 & 22 students & \\
\hline & SS3 & 25 students & \\
\hline \multirow{3}{*}{$\begin{array}{c}\text { Girls' Secondary school, } \\
\text { Achina }\end{array}$} & SS1 & 20 students & \multirow{3}{*}{67 students } \\
\hline & SS2 & 22 students & \\
\hline & SS3 & 25 students & \\
\hline \multirow{3}{*}{$\begin{array}{l}\text { Capital City Secondary } \\
\text { School, Awka }\end{array}$} & SS1 & 20 students & \multirow{3}{*}{67 students } \\
\hline & SS2 & 22 students & \\
\hline & SS3 & 25 students & \\
\hline \multirow{3}{*}{$\begin{array}{c}\text { Girls' Secondaty School, } \\
\text { Awka }\end{array}$} & SS1 & 20 students & \multirow{3}{*}{67 students } \\
\hline & SS2 & 22 students & \\
\hline & SS3 & 25 students & \\
\hline \multirow{3}{*}{$\begin{array}{c}\text { Anglican Girls } \\
\text { Secondary School, } \\
\text { Onitsha }\end{array}$} & SS1 & 20 students & \multirow{3}{*}{67 students } \\
\hline & SS2 & 22 students & \\
\hline & SS3 & 25 students & \\
\hline \multirow{3}{*}{$\begin{array}{c}\text { Christ the king College } \\
\text { Onitsha }\end{array}$} & SS1 & 20 students & \multirow{3}{*}{67 students } \\
\hline & SS2 & 22 students & \\
\hline & SS3 & 25 students & \\
\hline Total & & 402 Students & 402 students \\
\hline
\end{tabular}

At this point, a simple random sampling was further employed to select the specific number of students (67) required in each of the classes. Becuae of the near evenness of the number of students in the various class levels, allocation of study units was done by dividing the total number of students (402) by the total number of secondary schools (6).

\section{RESULTS}

We distributed 402 copies of the questionnaire and had 391 copies returned, representing a $98 \%$ return rate. We adjudged this appreciable enough to continue the study.

Our data reveal that students in SS3 were relatively more in number. This was because they were already in the exam classes, and thus they are, apparently, more exposed to communication interventions more than their junior colleagues. Also, the students' age bracket show that a majority of them (86\%) were 15 years and above. This was due to our concentration on only the senior students of the schools, from SS1 to SS3 because we deemed them mature and relatively more exposed when compared to the students in the junior classes. 


\section{Students' Exposure}

Table 4: Exposure to Interventions on Open Defecation

\begin{tabular}{cccc}
\hline $\begin{array}{c}\text { Heard/Seen any } \\
\text { Intervention on Open } \\
\text { Defecation? }\end{array}$ & $\begin{array}{c}\text { Percentages (\%) } \\
(\mathbf{N}=391)\end{array}$ & $\begin{array}{c}\text { Aware of the PEWASH } \\
\text { Program? }\end{array}$ & $\begin{array}{c}\text { Percentages (\%) } \\
(\mathbf{N}=391)\end{array}$ \\
\hline Yes & $100 \%$ & Yes & $(\mathrm{N}=19)$ \\
No & $(\mathrm{N}=391)$ & No & $95 \%$ \\
Total & - & Total & $(\mathrm{N}=372)$ \\
& $100 \%$ & & $100 \%$ \\
$(\mathrm{~N}=391)$ & $(\mathrm{N}=391)$
\end{tabular}

This table shows that the students were entirely aware of the interventions against the practice of open defecation due to the fact they were being cautioned against the practice by the schools' management but were found to be very poorly $(5 \%)$ aware of the Federal government PEWASH campaign, through which it is hoped that Nigeria will eliminate open defecation by 2025 and achieve $100 \%$ access to rural water supply and improved sanitation by 2030 .

\section{Students Medium of Exposure}

Table 5: Medium of Exposure to the interventions

\begin{tabular}{cc} 
Medium & $\begin{array}{c}\text { Percentages (\%) } \\
(\mathbf{N}=\mathbf{3 9 1})\end{array}$ \\
Word of Mouth & $57 \%$ \\
Television & $(\mathrm{N}=225)$ \\
Radio & $9 \%$ \\
Posters & $(\mathrm{N}=35)$ \\
Wall Writings & $18 \%$ \\
Total & $(\mathrm{N}=72)$ \\
& $1 \%$ \\
& $(\mathrm{~N}=3)$ \\
& $14 \%$ \\
\hline
\end{tabular}

This table shows the various media through which the students get exposed to the interventions. It is interesting that $57 \%$ of them get the messages via word of mouth; others get it through Television (9\%), radio (18\%), posters $(1 \%)$ and then writings on some walls instructing them not to defecate or urinate in such places $(14 \%)$. The dominant finding is that there is awareness of the interventions among them though not mainly received by the media; but still discussed and passed on to them through other means, especially 'word of mouth'interpersonal communication.. 
Table 6: Regularity of the Interventions

How often the interventions are received

\begin{tabular}{cc} 
How often the interventions are received & $\begin{array}{c}\text { Percentages }(\%) \\
(\mathbf{N}=391)\end{array}$ \\
\hline Regularly & $29 \%$ \\
Occasionally & $(\mathrm{N}=112)$ \\
Never & $71 \%$ \\
Total & $(\mathrm{N}=279)$ \\
& $100 \%$ \\
& $(\mathrm{~N}=391)$ \\
\hline
\end{tabular}

This table shows the regularity of the interventions on open defecation, showing that they are not regularly received by the students as only $29 \%$ of them claimed to be regularly exposed to the interventions as against $71 \%$ of who said they were not.

Table 7: Sources of the interventions

\begin{tabular}{cc} 
Originators & Percentages (\%) \\
& $(\mathbf{N}=\mathbf{3 9 1})$ \\
\hline School Management & $57 \%$ \\
NGOs & $(\mathrm{N}=223)$ \\
Undisclosed sources & $10 \%$ \\
International organizations/ Government & $(\mathrm{N}=37)$ \\
& $27 \%$ \\
Total & $(\mathrm{N}=107)$ \\
& $6 \%$ \\
& $(\mathrm{~N}=24)$ \\
& $100 \%$ \\
\hline
\end{tabular}

This table shows that the interventions on open defecation that the students are mostly exposed to was the caution by the school management that they should not mess up the school premises. Though they claimed earlier in this study to have been exposed to the federal government ongoing PEWASH program, they also claimed to have been exposed to some of the international programs on child mortality which reveals that one of the primary causes of child death is due to infections and environmental pollution, often attributed to open defecation. 


\section{Students' Practice of Open Defecation}

Table 8: Practicing open defecation? And Observing fellow students practicing it?

\begin{tabular}{cccc}
\hline $\begin{array}{c}\text { Practicing open } \\
\text { defecation? }\end{array}$ & $\begin{array}{c}\text { Percentages (\%) } \\
(\mathbf{N}=391)\end{array}$ & $\begin{array}{c}\text { Observing fellow students } \\
\text { practicing open defecation? }\end{array}$ & $\begin{array}{c}\text { Percentages (\%) } \\
(\mathbf{N}=391)\end{array}$ \\
\hline Yes & - & Yes & $86 \%$ \\
No & $100 \%=335)$ & $14 \%$ & $(\mathrm{~N}=56)$ \\
Total & $(\mathrm{N}=391)$ & No & $100 \%$ \\
& $100 \%$ & Total & $(\mathrm{N}=391)$ \\
\hline
\end{tabular}

This table reveals that whereas the students claim that they do not practice open defecation, a greater number among them $(86 \%)$ still agree to have seen or witnessed fellow students practice open defecation. This justifies that open defecation is still in practice within the schools

\section{Reasons behind the Students' Practice of Open Defecation}

Table 9: Sufficiency of Toilet Facility? And, preference to defecate in the open?

\begin{tabular}{cccc}
\hline $\begin{array}{c}\text { Sufficiency of Toilet } \\
\text { Facility? }\end{array}$ & $\begin{array}{c}\text { Percentages }(\%) \\
(\mathbf{N}=391)\end{array}$ & $\begin{array}{c}\text { Preference to defecate in } \\
\text { the open? }\end{array}$ & $\begin{array}{c}\text { Percentages }(\%) \\
(\mathbf{N}=\mathbf{3 9 1})\end{array}$ \\
\hline Yes & - & Yes & - \\
No & $100 \%$ & No & $100 \%$ \\
& $(\mathrm{~N}=391)$ & & $(\mathrm{N}=391)$ \\
Total & $100 \%$ & Total & $100 \%$ \\
& $(\mathrm{~N}=391)$ & & $(\mathrm{N}=391)$ \\
\hline
\end{tabular}

Earlier in the literature, it was argued that lack of latrines is the major factor why people indulge in the practice of open defecation. This study found as presented in Table 9 that there is still insufficiency of toilet facility in the schools; thereby justifying the assertion earlier made in the literature. However, this study further showed that the students do not have willingness or preference to defecate in the open, as claimed by some literature. It is also interesting to observe at this point that one major reason for possible practice of open defecation is insufficient toilet facilities. While the eradication of the practice of open defecation and the process of making people follow good sanitation and hygienic practices is still a challenge for most nations, the actual coverage/use of toilets is much lower than what statistics suggest (Arulchevan. \& Uma, 2013). 


\begin{tabular}{cc}
\hline $\begin{array}{c}\text { Frequency of Washing the Toilet } \\
\text { Once a day }\end{array}$ & $\begin{array}{c}\text { Percentages (\%) } \\
(\mathbf{N}=391)\end{array}$ \\
Once a week & $10 \%$ \\
& $(\mathrm{~N}=36)$ \\
several times a week & $7 \%$ \\
once a month & $(\mathrm{N}=26)$ \\
once in a while & $14 \%$ \\
Total & $(\mathrm{N}=54)$ \\
& $(\mathrm{N}=130)$ \\
& $37 \%$ \\
\end{tabular}

To determine whether the neatness of the toilet facility contributed to rise in the practice of open defecation, this study considered the regularity at which the toilet facility is kept neat and tidy by the students. Results show that the toilets in most of the schools are mainly washed once in a while (37\%) and very poorly once in a month $(32 \%)$, even though some claimed to wash theirs more regularly; like once a day (10\%); once a week $(7 \%)$; several times a week $(14 \%)$. Hence, we are able to distinguish here that neatness of the toilet facility caused the students to engage in the practice of open defecation.

Table 11: Informing the School Management? And, how the Management is engage

\begin{tabular}{cccc}
\hline $\begin{array}{c}\text { Informing the } \\
\text { School } \\
\begin{array}{c}\text { Management about } \\
\text { the Condition of the } \\
\text { Toilet? }\end{array}\end{array}$ & $\begin{array}{c}\text { Percentages }(\%) \\
(\mathbf{N}=391)\end{array}$ & $\begin{array}{c}\text { And how they engage } \\
\text { management in the issue } \\
\text { of toilet Neatness }\end{array}$ & $\begin{array}{c}\text { Percentages }(\%) \\
(\mathbf{N}=391)\end{array}$ \\
\hline Yes & $100 \%$ & Reporting violators & $86 \%$ \\
No & $(\mathrm{N}=391)$ & Nominating Sanitary & $(\mathrm{N}=335)$ \\
& - & Prefects & $14 \%$ \\
Total & Total & $(\mathrm{N}=55)$ \\
& $100 \%$ & & $100 \%$ \\
$(\mathrm{~N}=391)$ & & $(\mathrm{N}=391)$ \\
\hline
\end{tabular}

This table also considered the action taken by the students to ensure compliance against the warning by the school management concerning the practice of open defecation. It was discovered that all the students were not comfortable with the practice and confirmed that the managements were aware of the situation of their toilet facilities. They involved the managements sometimes when some students keep messing the toilet up to the detriment of their health. They also agreed to sometimes involve the management in the nomination of capable sanitary prefects who assist to keep the toilet very neat and tidy all the time. Arulchevan. \& Uma (2013) found that the major cause of open defecation is the lack of awareness on sanitation, arguing also that an effective hygiene education can contribute to creating awareness, understanding and behaviour change on sanitation. 
Table 12: Challenges with the toilet Facility

\begin{tabular}{cc}
$\begin{array}{c}\text { Challenges being encountered while using the toilet } \\
\text { Facility }\end{array}$ & $\begin{array}{c}\text { Percentages (\%) } \\
(\mathbf{N}=\mathbf{3 9 1})\end{array}$ \\
\hline Students' Carelessness & $86 \%$ \\
Water Scarcity & $(\mathrm{N}=335)$ \\
Total & $14 \%$ \\
& $(\mathrm{~N}=56)$ \\
& $100 \%$ \\
\end{tabular}

This work was also able to discover the peculiar challenges being faced by the students while attempting to keep the toilet facility in order. Two major challenges they encounter are the students' carelessness $(86 \%)$ and scarcity of water $(14 \%)$. In line with this study, almost one-tenth of the global disease burden could be prevented by improving water supply, basic sanitation, and hygienic practices (Canaday, 2011; Bill and Melinda Gates Foundation, 2011; WHO and UNICEF, 2004). Such improvement will no doubt reduce child mortality and improve health and nutritional status of many children around the world whom fecal-oral contamination is responsible for more than 50 percent of deaths yearly in the developing world. School-based sanitation promotion (SBSP) is also considered to bring both health and non-health related benefits to children, such as maintaining high school attendance, promoting gender equity and establishing life-long healthy practices (Curtis ,2005, Ebong 1994, IRC, WSSCC 2004).

\section{STUDENTS'ADHERENCE TO THE INTERVENTIONS}

Table 13: Any effect of the interventions to reduce practice? Do they adhere?

\begin{tabular}{cccc}
\hline Any effect? & $\begin{array}{c}\text { Percentages }(\%) \\
(\mathbf{N}=\mathbf{3 9 1})\end{array}$ & $\begin{array}{c}\text { Adherence? } \\
(\mathbf{N}=\mathbf{3 9 1})\end{array}$ & $\begin{array}{c}\text { Percentages }(\%) \\
\text { Yes }\end{array}$ \\
No & - & Yes & $100 \%$ \\
& $100 \%$ & No & $(\mathrm{N}=391)$ \\
Total & $(\mathrm{N}=391)$ & Total & $100 \%$ \\
& $100 \%$ & & $(\mathrm{~N}=391)$ \\
\hline
\end{tabular}

The study also found that the interventions on open defecation had relatively no behaviour change effect on the students under study. They had earlier denied participating in open defecation but rather accept having witnessed other students indulging in it. Here, they entirely neither accepted to being influenced by the interventions nor adhere to the message, having denied being guilty of the practice ab initio.

Table 14: Regulations?

\begin{tabular}{|c|c|}
\hline Any regulatory mechanisms? & $\begin{array}{c}\text { Percentages }(\%) \\
\qquad(\mathrm{N}=391)\end{array}$ \\
\hline Yes & $\begin{array}{c}57 \% \\
(\mathrm{~N}=223)\end{array}$ \\
\hline No & $\begin{array}{c}43 \% \\
(\mathrm{~N}=168)\end{array}$ \\
\hline Total & $\begin{array}{c}100 \% \\
(\mathrm{~N}=391)\end{array}$ \\
\hline
\end{tabular}


The study further established that there are regulatory mechanisms against the practice of open defecation in the schools and also around the communities where the schools are domiciled. The community sometimes set up a watch group that searches for those who participate in the practice and sometimes the management of the schools instructs the prefects and the security personnel to help catch those who practice such within the school premises.

\section{Behaviour change effect}

Table 15: understood the interventions and quitting open defecation? And exposure, affecting the attitude towards the practice?

\begin{tabular}{cccc}
\hline $\begin{array}{c}\text { Understood the } \\
\text { interventions and } \\
\text { quitting open } \\
\text { defecation? }\end{array}$ & $\begin{array}{c}\text { Percentages }(\%) \\
(\mathbf{N}=391)\end{array}$ & $\begin{array}{c}\text { Exposure affecting the } \\
\text { attitude towards the } \\
\text { practice? }\end{array}$ & $\begin{array}{c}\text { Percentages }(\%) \\
(\mathbf{N}=391)\end{array}$ \\
\hline Agree & $51 \%$ & Agree & $2 \%$ \\
$(\mathrm{~N}=200)$ & Strongly Agree & $(\mathrm{N}=10)$ \\
Strongly Agree & $44 \%$ & Disagree & $5 \%$ \\
Disagree & $(\mathrm{N}=171)$ & & $(\mathrm{N}=19)$ \\
Strongly disagree & $3 \%$ & $50 \%$ \\
& $(\mathrm{~N}=12)$ & Strongly disagree & $(\mathrm{N}=197)$ \\
Undecided & $2 \%$ & & $41 \%$ \\
& $(\mathrm{~N}=8)$ & Undecided & $(\mathrm{N}=159)$ \\
Total & - & Total & $2 \%$ \\
& $100 \%$ & & $(\mathrm{~N}=6)$ \\
& $(\mathrm{N}=391)$ & $100 \%$ & $(\mathrm{~N}=391)$ \\
\hline
\end{tabular}

The trends in the findings appear ambivalent as the students are basically evasive of their practice of open defecation but rather attests to have witnessed others doing so. They agreed (51\%) and strongly agreed (44\%) to have understood the interventions and attempting quitting the practice but not essentially by the conventional media but rather by instructions given by the management that they must not lither the premises. In order words their alleged non practice of open defecation is somehow related to the warnings and crusade by the school management that they should desist from the act and not essentially from the media and other sources. This further implies the interventions need to consider the media of communication through which these students would easily be exposed to interventions. Such includes seminars, teachings and the like within the school premises; given also the fact that their exposure to the conventional media might be limited due to their demographic characteristics and then because some of them live inside the school dormitory where the media facilities are relatively scarce and not allowed. However, they further disagreed (50\%) and strongly disagreed $(41 \%)$ that their attitudes or perceptions changed as a result of their exposure to the interventions which further point at the need for more sensitization of the students on the dangers of open defecation practice.

\section{DISCUSSION}

For the purpose of equality, three PPSSC zones were selected out of the six zones, in view of the three senatorial zones in Anambra state. For uniformity in the questionnaire distribution, 67 student respondents were allotted to each of the schools which sums up to 402 persons and as such, copies of the questionnaire were distributed to all of them and only 391 copies were returned which represented a $98 \%$ return rate. The study shows a more equal representation of the senior classes with those of them in the SS3 relatively more in number because they are already in the exam classes and are adjudged to be more exposed to the interventions than their junior colleagues; 86 percent of them were also found to be 15 years and above owing to the more concentration on the senior students of the schools, 
It is noteworthy that these students are entirely aware of interventions against the practice of open defecation, but not basically campaigns or programs from the conventional media but warnings against the practice from the schools or elsewhere. In terms of the Federal government PEWASH campaign, the study found that only 5\% of the students were aware of such; which is relatively low. In terms of medium that exposed them to the interventions, this study found that $57 \%$ of them got the messages via word of mouth, others got them through Television $(9 \%)$; radio $(18 \%)$; posters $(1 \%)$ and then writings on some walls showing that they should not defecate or urinate in strategic places (14\%). The striking thing is that there is awareness, though not mainly received from the media, but still discussed and passed among them, even though those messages are not regularly received by the students.

This study also revealed that the interventions on open defecation that these students were mostly exposed to is the warning and caution by the school management that they should not mess up the school premises but should always keep them very clean. Though they claimed earlier in this study to have been exposed to the federal government ongoing PEWASH program, they also claim to have been exposed to the some of the international programs especially on child mortality where they learnt that one of the primary causes of child death was infections and environmental pollution, often attributed to open defecation. While they claim not to practice open defecation, a greater number of them (86\%) still agree to have seen or witnessed fellow students do so, justifying the existence of such in the schools. Awe \& Nadar (2016, p. 2) had also observed that over 70 million people do not have access to improved sanitation around the globe with more than 45 million people practicing open defecation that threaten the health of the people, which was part of the reasons, the National Council on Water Resources at the 2014 council meeting recommended the development of an Open Defecation Free (ODF) Roadmap for Nigeria.

Having noticed earlier in the literature, that lack of latrines is the major factor why people defecate in the open; this study revealed that there is still inadequate of toilet facilities in the schools, thereby justifying this claim in the literature that students do not have willingness or preference to defecate in the open. This also debunked another claim already made in the literature that people prefer to defecate in the open because it is more convenient and pleasurable. With regard to the insufficiency of toilet facilities, and in line with the already existing issue of health problems of the Nigerian people, this work advocates for an improved sanitary facilities in the schools, without such, eradication of the practice of open defecation and the process of making students follow good sanitation and hygienic practices is still a challenge. The study further considered whether the neatness of the toilet facility contribute to rise in the practice of open defecation, by looking at the regularity at which the toilet facility is kept neat by the students. Results show that the toilets in most of the schools are mainly washed once in a while (37\%) and very poorly once in a month (32\%), even though some claimed to wash theirs more regularly.

In terms of actions taken by the students to ensure compliance with the warning by the school management concerning the practice of open defecation, it was discovered that all the students are not comfortable with the practice and also confirm the management awareness of the situation of their toilet facility and how they involve them sometimes especially when some students keep messing the toilet up. They also agreed to sometimes liaise with the management to nominate sanitary prefects who assist to keep the toilet neat and tidy. This is in line with Arulchevan. \& Uma (2013)'s discovery that the major cause of open defecation is the lack of awareness on sanitation, and that an effective hygiene education can contribute to creating awareness, understanding and behaviour change on sanitation practices. Two major challenges they encounter, while attempting to keep the toilet facility in order are the students' carelessness $(86 \%)$ and scarcity of water $(14 \%)$.

Interestingly, while the students do not accept that they practice open defecation, they attest to have witnessed others doing so, although they agreed (51\%) and strongly agreed (44\%) to have understood the interventions not essentially by the conventional media but rather by instructions given by the management that they must not litter the premises. In order words the non practice of open defecation is somehow related to the warnings and crusade by the school management that they should desist from the act and not essentially from the media and other sources.

\section{CONCLUSION}

We concluded, going by the results of this study, that the practice of Open defecation was a major challenge within the Nigerian public schools, thereby leading to several health problems, hence the need for subsequent empirical research on school management, to see how they perceive the federal government PEWASH program; how far they have gone in observing it, and then how they can assist in achieving the core objective of the 
program such that a safe and healthy environment is retained in the Nigerian society, especially within the schools where they teach.

Though the students may likely not wish to disclose the fact that they indulge in the practice of open defecation as evident in this study, there is need for a qualitative participant observation study to help reveal the exact level of practice of open defecation by these students such that better solutions on how the problem could be more efficiently handled would be proffered.

\section{RECOMMENDATIONS}

In line with the foregoing, the following recommendations were made:

1. More intensive sensitization campaigns against the practice of open defecation in Nigeria should be organized for In-school students which should overtime be evaluated and monitored to assess results. This should include seminars, teachings and the like within the school premises;

2. The campaigns should accommodate some traditional media and interpersonal group teachings targeted at these students to ensure that the messages are received; given the fact that their exposure to the conventional media might be limited due to their demographic characteristics and because some of them live in the school dormitory where media facilities are relatively scarce and not allowed;

3. There should be regular supervision of infrastructure in the schools especially the toilet facilities.

4. Subsequent studies on teachers' perception and regulatory mechanisms against the students' indulgence in open deflation should be conducted as participant observations, which would reveal the exact level of students' practice of open defecation.

\section{REFERENCES}

Adamu, S. H. (2017). Open defecation in Nigeria. Retrieved online @ http//www.opendefecation .ng.org on the on the 1 st June, 2017

Ahmad, J. (2014). "How to eliminate open defecation by 2030" Retrieved 2 June 2017. Progress on drinking water and sanitation (2014) WHO/UNICEF Joint Monitoring Programme for Water Supply and Sanitation (JMP).

Arku R. E., Vallarino R., Dionisio K. L., Hyunok Choi R. L, Wilson J. G., Hemphill C., Agyei- $\quad$ Mensah S., Spengler J. D., Ezzati M. (2008) Charactering air pollution in two low income. Journal of Science of the total environment. Volume 402, Issue 2

Arulchevan S. \& Uma M. (2013). Integrated Communication Strategy for Creating Awareness on Sanitation and Hygiene Behavior Change. The International Journal of Communication and Health Volume 2, Issue 1

Awe, Emmanuel Olusola \& Nadar, Kannan (2016). Nigerian Situation in Open Defecation Practice. The International Journal of Communication and Health Volume 2, Issue 1

Bill \& Melinda Gates Foundation (2011). Malaria forum. Online at 2011Malaria Forum Bill $\quad \&$ MelindaGatesFoundation.htm

Boisson, Sosai , Ray Shubajyoti, Routray, Parimita, Torondel Belen, Schmidt Wolf-Peter, Bishakha and Clasen Thomas (2014). 'Promoting latrine construction and use in practicing open defecation: process evaluation in connection with a randomized Orissa, India'. Ife Journal of Science vol. 18, no. 4. Available online

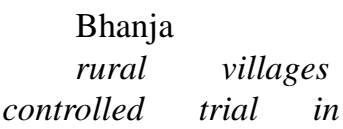
http://www.interesjournals.org/JMMS 
Canaday C. (2011). Simple urine-diverting dry toilets built with recycled or readily available materials. Sustainable Sanitation Practice, 1(6):4-9. (http//www.ecosan.at/ssp).

Clasen T; Boisson S.; Routray; Torondel (2014). "Effectiveness of a rural sanitation programme on diarrhoea, soil-transmitted helminth infection, and child malnutrition in Odisha, India: a cluster-randomised trial". The Lancet Global Health. 2 (11): e645-e653.

Conant J. \& Fadem P. (2008). A Community Guide to Environmental Health. Hesperian Foundation, Berkeley, C A, USA, (http://www.hesperian.org).

Croghan E. (2002). A survey of drinking and toilet facilities in local state schools. Br J Community Nurs, 7(2):76-79.

Curtis V. (2005). Hygiene and Sanitation in Vietnam. In Report of a Mission 7-22 May 2005 London. Hygiene Center, London School of Hygiene and Tropical Medicine; 2005, 68.

Ebong R. (1994): Environmental health knowledge and practice survey among secondary schoolchildren in Zaria, Nigeria. Environ Health Perspect, 102(3):310-312.

IRC, WSSCC (2004): School Sanitation and Hygiene Education Symposium, the Way Forward: Construction is not Enough. Ife Journal of Science vol. $\quad 18, \quad$ no. $4 . \quad$ Available $\quad$ online http://www.interesjournals.org/JMMS

Lorna F, Kaufmann RB, David K, Wayne E, Laurence H, Colford JM (2005): Water, sanitation, and hygiene interventions to reduce diarrhoea in less developed countries: a systematic review and meta-analysis. Lancet Infect Dis, 5:42-52.

Lundblad B (2005): Perceptions of school toilets as a cause for irregular toilet habits among schoolchildren aged 6 to 16 years. Journal of School Health, 75(4):125-128.

Nuzhat C., Mohammad A. (2006): Exploring the Current Status of Sanitary Latrine use in Shibpur Upazila, Narsingdi District. BRAC Research Report.

UNICEF, IRC (1998): A manual on School Sanitation and Hygiene. Retrieved Online @ http//www.unicef.org.ng on $20^{\text {th }}$ August, 207

UN-Habitat (2003). The Challenge of Slums - Global Report on Human Settlements 2003. United Nations Human Settlements Programme, Earthscan Publications Ltd., London, UK.

Vernon S, Lundblad B, Hellstrom A (2003). Children's Experiences of School Toilets Present a Risk to their Physical and psychological Health. Child Care, Health \& Development, 1:47-53. 